\title{
Abnormal intestinal bile acid distribution in azotaemic man: a possible role in the pathogenesis of uraemic diarrhoea
}

\author{
S. J. GORDON, ${ }^{1}$ L. J. MILlER, L. J. HAEFFNER, M. D. KINSEY, AND \\ O. D. KOWLESSAR
}

From the Jefferson Medical College, Thomas Jefferson University, Philadelphia, Pennsylvania, U.S.A.

SUMMARY Proximal intestinal bile acids have been studied in 14 ambulatory patients with varying degrees of azotaemia. When compared with normal subjects, the azotaemic patients showed a significant decrease in deoxycholic acid. Analysis of faecal bile acids of a patient with low intestinal deoxycholic acid also showed low deoxycholic acid with a preponderance of primary bile acids, in contrast with faecal bile acids of a normal subject and a patient with normal intestinal deoxycholic acid. It is suggested that impairment of deconjugation or $7 a$-dehydroxylation might be contributing to the low deoxycholic acid observed in azotaemic patients. Unusual bile acids: ursodeoxycholic acid, 3-hydroxy-7-keto-cholanic acid, and 3,12-dihydroxy-7-keto-cholanic acid were also noted in intestinal aspirates of azotaemic patients. The presence of these bile acids in conjunction with low deoxycholic acid correlates with the symptom of diarrhoea in azotaemic patients, and may contribute to the pathogenesis of diarrhoea in these patients.

Anorexia, nausea, vomiting, and diarrhoea are common gastrointestinal complaints associated with the uraemic state. The cause of these symptoms in the azotaemic patient remains obscure. It is generally accepted that toxic materials capable of producing the uraemic syndrome are produced in the gastrointestinal tract, probably as a result of bacterial metabolism of substrates not excreted by these patients. Eirheber and Carter (1966) have demonstrated that germ-free rats rendered uraemic by bilateral nephrectomy significantly outlived uraemic animals with conventional flora. Furthermore, Jaffe and Laing (1934) have correlated gastrointestinal lesions in uraemic patients with areas of bacterial proliferation.

Bile acids represent one of the most important substrates for bacterial metabolism within the gut lumen. Abnormalities of luminal bile acids have been implicated in gastrointestinal symptoms of man, such as diarrhoea, malabsorption and upper gastrointestinal dysfunction. Of note, Drüeke et al. (1972) have demonstrated that bile acids affect jejunal function in the uraemic rat, possibly secondary to membrane changes.

${ }^{1}$ Address for communications: Dr Susan J. Gordon, Division of Gastroenterology, Jefferson Medical College, 1025 Walnut Street, Philadelphia, Pennsylvania, 19107, U.S.A.

Received for publication 29 October 1975
In order to elucidate more clearly the pathophysiology of gastrointestinal problems in uraemic patients, the proximal intestinal bile acid pattern in azotaemic patients with and without gastrointestinal symptoms has been studied. Faecal bile acids were also studied in selected azotaemic patients.

\section{Methods \\ PATIENTS AND SUBJECTS}

The normal subjects included nine healthy volunteers, six females, and three males, 21 to 45 years old.

The patient population consisted of 14 ambulatory patients with azotaemia; two with mild azotaemia, three with severe azotaemia without haemodialysis, and nine undergoing a chronic haemodialysis programme. The clinical status of the azotaemic patients is summarized in Table 1. All renal diagnoses but one (M.E.) were confirmed by biopsy.

Patients with mild azotaemia were on unrestricted diets. Those with severe azotaemia without haemodialysis were on essential amino acid diets (Giovannetti and Maggioce, 1964). Those on haemodialysis were on standard dialysis diets with restriction of protein, salt, and water as determined by their metabolic status. Only two patients (J.B. and V.C.) had significant anorexia. 


\begin{tabular}{|c|c|c|c|c|c|c|c|c|}
\hline$P t$ & Age & $\operatorname{Sex}$ & Race & Renal diagnosis & $\begin{array}{l}\text { Serum } \\
\text { creatinine } \\
(m g \%)\end{array}$ & $\begin{array}{l}\text { Hepatic } \\
\text { function* }\end{array}$ & $M N C \dagger$ & Gastrointestinal symptoms \\
\hline \multicolumn{9}{|c|}{ Mild azotaemia } \\
\hline J.R. & 39 & $\mathbf{M}$ & $\mathbf{B}$ & Diabetic glomerulosclerosis & $2 \cdot 9$ & Normal & ND & $\begin{array}{l}\text { Severe diarrhoea ; malabsorp- } \\
\text { tion syndrome }\end{array}$ \\
\hline E.C. & 51 & $\mathbf{M}$ & W & Interstitial nephritis & $3 \cdot 4$ & Normal & ND & $\begin{array}{l}\text { Severe watery diarrhoea, weight } \\
\text { loss, history peptic ulcer } \\
\text { disease }\end{array}$ \\
\hline \multicolumn{9}{|c|}{ Severe azotaemia without haemodialysis } \\
\hline W.P. & 47 & $\mathbf{M}$ & $\mathbf{W}$ & Renal amyloidosis & $10 \cdot 8$ & Normal & ND & $\begin{array}{l}\text { Severe watery diarrhoea, nausea, } \\
\text { vomiting, weight loss }\end{array}$ \\
\hline J.B. & 16 & $\mathbf{M}$ & $\mathbf{W}$ & $\begin{array}{l}\text { Chronic membranoprolif- } \\
\text { erative glomerulonephritis }\end{array}$ & $12 \cdot 5$ & Normal & + & Severe nausea, vomiting \\
\hline H.D. & 63 & $\mathbf{F}$ & $\mathbf{B}$ & Chronic pyelonephritis & $18 \cdot 2$ & Normal & ND & None \\
\hline \multicolumn{9}{|c|}{ Severe azotaemia with haemodialysis } \\
\hline $\begin{array}{l}\text { A.H. } \\
2 \text { yr } \ddagger\end{array}$ & 50 & $\mathbf{F}$ & B & Diabetic glomerulosclerosis & $15 \cdot 9$ & Normal & ND & Severe watery diarrhoea \\
\hline $\begin{array}{l}\text { L.M. } \\
1 \text { yr }\end{array}$ & 30 & $\mathbf{M}$ & $\mathbf{W}$ & Chronic glomerulonephritis & $15 \cdot 6$ & $\begin{array}{l}\text { Biopsy: chronic } \\
\text { persistent } \\
\text { hepatitis }\end{array}$ & + & $\begin{array}{l}\text { Mild diarrhoea, nausea, } \\
\text { vomiting, history peptic ulcer } \\
\text { disease }\end{array}$ \\
\hline $\begin{array}{l}\text { J.J. } \\
2 \mathrm{yr}\end{array}$ & 43 & $\mathbf{M}$ & $\mathbf{B}$ & Malignant nephrosclerosis & $15 \cdot 9$ & Normal & + & $\begin{array}{l}\text { Severe diarrhoea, malabsorp- } \\
\text { tion syndrome }\end{array}$ \\
\hline $\begin{array}{l}\text { V.C. } \\
3 \text { yr }\end{array}$ & 49 & $\mathbf{F}$ & $\mathbf{W}$ & Systemic amyloidosis & $7 \cdot 2$ & $\begin{array}{l}\text { Biopsy: intra- } \\
\text { hepatic chole- } \\
\text { stasis, amyloid- } \\
\text { osis }\end{array}$ & + & Anorexia, vomiting \\
\hline $\begin{array}{l}\text { S.G. } \\
2 \mathrm{yr}\end{array}$ & 40 & $\mathbf{F}$ & $\mathbf{B}$ & Chronic pyelonephritis & $12 \cdot 3$ & Normal & + & $\begin{array}{l}\text { Severe watery diarrhoea, post- } \\
\text { vagotomy }\end{array}$ \\
\hline L.A. & 21 & $\mathbf{M}$ & B & $\begin{array}{l}\text { Chronic proliferative } \\
\text { glomerulonephritis }\end{array}$ & $15 \cdot 5$ & Normal & ND & $\begin{array}{l}\text { Predialysis diarrhoea, } 2 \text { formed } \\
\text { stools/day on dialysis }\end{array}$ \\
\hline $\begin{array}{l}\text { C.F. } \\
3 \text { yr }\end{array}$ & 66 & $\mathbf{M}$ & $\mathbf{W}$ & Chronic glomerulonephritis & $19 \cdot 2$ & Normal & + & $\begin{array}{l}\text { Predialysis diarrhoea, } 2 \text { formed } \\
\text { stools/day on dialysis, } \\
\text { asymptomatic steatorrhea }\end{array}$ \\
\hline $\begin{array}{l}\text { C.S. } \\
6 \mathrm{mo}\end{array}$ & 26 & $\mathbf{F}$ & $\mathbf{B}$ & $\begin{array}{l}\text { Chronic proliferative } \\
\text { glomerulonephritis }\end{array}$ & $17 \cdot 5$ & Normal & ND & $\begin{array}{l}\text { Predialysis diarrhoea, } 2 \text { formed } \\
\text { stools/day on dialysis }\end{array}$ \\
\hline $\begin{array}{l}\text { M.E. } \\
1 \mathrm{yr}\end{array}$ & 58 & $\mathbf{M}$ & W & $\begin{array}{l}\text { Malignant nephrosclerosis } \\
\text { with renal artery stenosis }\end{array}$ & $11 \cdot 4$ & Normal & ND & Constipation \\
\hline
\end{tabular}

Table 1 Clinical summary of azotaemic patients

*Bilirubin, SGPT, 5' nucleotidase, hepatitis associated antigen.

$\dagger$ Motor nerve conduction study, $+=$ normal study, ND = not done. $\ddagger$ Duration of haemodialysis.

\section{PROCEDURES}

After an overnight fast, a modified Cantor tube was positioned at the ligament of Treitz under fluoroscopic guidance. The patients and subjects were given a simple test meal of tea with sugar and one slice of buttered toast, and 30 minutes after the meal, intestinal samples were aspirated at this location. In one patient (J.J.) the tube was then allowed to pass down the small intestine to the mid-ileum where aspiration of intestinal material was repeated. Fosition in the mid-ileum was confirmed by radiography with installation of radio-opaque contrast medium.

Random stools were collected from two azotaemic patients (J.J. and C.S.) and compared with that of a r ormal subject.

pH of intestinal samples and faecal homogenates was recorded by glass electrode immediately after collection.

The anaerobic and aerobic microflora of intestinal and faecal samples were assessed quantitatively. This study will be reported separately.
BILE ACID ANALYTICAL TECHNIQUES

Total bile acid distribution Intestinal fluid for bile acid assay was prepared according to techniques previously reported (Haeffner et al., 1976a). The methyl ester-trifluoroacetate derivatives were subjected to gas liquid chromatographic analysis on glass columns $(4 \mathrm{~mm}$ i.d. $\times 1.2 \mathrm{~m})$ packed with $2 \%$ QF-1 on 100/200 Gas Chrom Q (Applied Science Laboratories, State College, $\mathrm{Pa}$.) using hydrogen flame ionization detector.

Faecal samples were prepared for chromatography by the method of Grundy et al. (1965) and the methyl ester-trifluoroacetate derivatives were chromatographed under the same conditions as described for intestinal samples. Faecal unconjugated bile acids were determined by the same method, with the exclusion of alkaline hydrolysis of samp'es before gas liquid chromatography.

Total bile acid concentration Quantitative measurements of total bile acid concentration of intestinal samples were carried out using the 3-hydroxysteroid 
dehydrogenase enzyme assay of Iwata and Yamasaki (1964).

Conjugated bile acid distribution Intestinal fluid was prepared for thin layer chromatography as reported elsewhere (Haeffner et al., 1976b). Taurine conjugates and glycine conjugates were separated using the SII solvent system described by Hofmann (1962), and were detected by iodine vapour. The glycine conjugates and taurine conjugates were assessed by the 3-hydroxysteroid dehydrogenase enzyme assay.

\section{IDENTIFICATION}

Bile acid peaks were identified on gas liquid chromatography by simultaneous injection of standard bile acids, including deoxycholic acid, cholic acid, lithocholic acid, ursodeoxycholic acid, 3-hydroxy-7keto-cholanic acid, and 3,12-dihydroxy-7-ketocholanic acid. Where standards were not available $(3 \alpha, 7 \beta, 12 \alpha$-trihydroxy-cholanic acid, $3 \beta, 12 \alpha$-dihydroxy-cholanic acid), a tentative identification was based on comparison of the relative retention times of the peak with the relative retention times of the standards recorded in the literature by Sjövall (1962). Thin layer chromatography was used to confirm the presence of unusual bile acids by simultaneous chromatography of appropriate stan- dard bile acids. Ursodeoxycholic acid and lithocholic acid were identified on the SII system, while 3-hydroxy-7-keto-cholanic acid and 3,12-dihydroxy7-keto-cholanic acid were identified on the isooctane:ethyl acetate:glacial acetic acid (5:5:1) system described by Bruusgaard (1970). Compounds were detected by iodine vapour and 2,4-dinitrophenylhydrazine.

\section{Results}

\section{TOTAL BILE ACID DISTRIBUTION}

The total bile acid distribution in the proximal small intestine after the test meal in normal subjects and all azotaemic patients is shown in Table 2. Azotaemic patients had a significant decrease in the percent deoxycholic acid, $12.0 \% \pm 9 \cdot 2$, when compared with normal subjects, $28.0 \% \pm 11 \cdot 2$ ( $P<0.005)$. There was no correlation between the level of the deoxycholic acid and the degree of azotaemia. In contrast, there was no significant difference between patients with azotaemia and normal subjects with respect to chenodeoxycholic acid and cholic acid.

Lithocholic acid was found in aspirates of all azotaemic patients with a mean of $3.0 \% \pm 0.8$. Ursodeoxycholic acid was significantly elevated in all azotaemic patients, mean $-5.9 \% \pm 5.3$ with a range from $1 \cdot 1$ to $17 \cdot 7 \%$. The percent ursodeoxy-

\begin{tabular}{|c|c|c|c|c|c|c|c|}
\hline$P t$ & $\begin{array}{l}\text { Lithocholic } \\
\text { acid }\end{array}$ & $\begin{array}{l}\text { Deoxycholic } \\
\text { acid }\end{array}$ & $\begin{array}{l}\text { Chenodeoxy- } \\
\text { cholic acid }\end{array}$ & $\begin{array}{l}\text { Ursodeoxy- } \\
\text { cholic acid }\end{array}$ & $\begin{array}{l}\text { Cholic } \\
\text { acid }\end{array}$ & $\begin{array}{l}\text { 3-hydroxy-7- } \\
\text { keto-cholanic } \\
\text { acid }\end{array}$ & $\begin{array}{l}\text { 3,12-dihydroxy- } \\
\text { 7-keto-cholanic } \\
\text { acid }\end{array}$ \\
\hline $\begin{array}{l}\text { Mild azotaem } \\
\text { J.R. } \\
\text { E.C. }\end{array}$ & $\begin{array}{l}2 \cdot 2 \\
4 \cdot 1\end{array}$ & $\begin{array}{l}7.5 \\
4.9\end{array}$ & $\begin{array}{l}63 \cdot 9 \\
46 \cdot 2\end{array}$ & $\begin{array}{l}17 \cdot 7 \\
15 \cdot 6\end{array}$ & $\begin{array}{r}8 \cdot 7 \\
25 \cdot 1\end{array}$ & $\begin{array}{l}\text { ND } \\
+\end{array}$ & $\begin{array}{l}\text { ND } \\
+\end{array}$ \\
\hline $\begin{array}{l}\text { Severe azotae } \\
\text { W.P. } \\
\text { J.B. } \\
\text { H.D. }\end{array}$ & $\begin{array}{c}\text { mic without } \\
\begin{array}{c}3 \cdot 4 \\
3 \cdot 3 \\
3 \cdot 7\end{array}\end{array}$ & $\begin{array}{r}\text { dialysis } \\
10 \cdot 2 \\
28 \cdot 4 \\
23 \cdot 7\end{array}$ & $\begin{array}{l}41 \cdot 6 \\
29 \cdot 4 \\
46 \cdot 3\end{array}$ & $\begin{array}{r}10 \cdot 3 \\
6 \cdot 2 \\
2 \cdot 4\end{array}$ & $\begin{array}{l}30 \cdot 3 \\
20 \cdot 4 \\
18 \cdot 9\end{array}$ & $\frac{t}{+}$ & $\begin{array}{l}+ \\
+ \\
+\end{array}$ \\
\hline $\begin{array}{l}\text { Severe azotae } \\
\text { A.H. } \\
\text { L.M. } \\
\text { J.J. } \\
\text { V.C. } \\
\text { S.G. } \\
\text { L.A. } \\
\text { C.F. } \\
\text { C.S. } \\
\text { M.E. }\end{array}$ & $\begin{array}{c}\text { emia with ho } \\
2.7 \\
2.7 \\
3.2 \\
2.6 \\
2 \cdot 1 \\
3.0 \\
2.1 \\
2.7 \\
4.8\end{array}$ & $\begin{array}{r}\text { lialysis } \\
1 \cdot 0 \\
12 \cdot 2 \\
1.6 \\
1.6 \\
13.7 \\
3 \cdot 8 \\
16 \cdot 8 \\
17 \cdot 3 \\
24.9\end{array}$ & $\begin{array}{l}25 \cdot 0 \\
27 \cdot 1 \\
42 \cdot 3 \\
40 \cdot 4 \\
35 \cdot 7 \\
32 \cdot 3 \\
14 \cdot 5 \\
35 \cdot 5 \\
35 \cdot 8\end{array}$ & $\begin{array}{l}7.9 \\
6.0 \\
3.5 \\
2.5 \\
1.5 \\
1.5 \\
1.4 \\
1.1 \\
4.7\end{array}$ & $\begin{array}{l}58 \cdot 6 \\
50 \cdot 0 \\
46 \cdot 7 \\
47 \cdot 1 \\
37 \cdot 3 \\
54 \cdot 0 \\
54 \cdot 5 \\
41 \cdot 6 \\
25 \cdot 4\end{array}$ & $\begin{array}{l}+ \\
+ \\
+ \\
+ \\
+ \\
+ \\
+ \\
+ \\
+\end{array}$ & $\begin{array}{l}+ \\
+ \\
+ \\
+ \\
+ \\
+ \\
+ \\
+ \\
+\end{array}$ \\
\hline $\begin{array}{l}\text { Mean } \pm S D \\
\text { Azotaemic } \\
\text { patients } \\
N=14\end{array}$ & $\begin{array}{r}3.0 \\
\pm 0.8\end{array}$ & $\begin{array}{r}12.0 \\
\pm 9.2\end{array}$ & $\begin{array}{r}36.9 \\
\pm 11 \cdot 7\end{array}$ & $\begin{array}{r}5.9 \\
\pm \quad 5 \cdot 3\end{array}$ & $\begin{array}{r}37 \cdot 0 \\
\pm 15 \cdot 6\end{array}$ & & \\
\hline $\begin{array}{l}\text { Mean } \pm \text { SD } \\
\text { Normal } \\
\text { subjects } \\
\mathbf{N}=9 \\
\mathbf{P}\end{array}$ & $\begin{array}{l}<1 \\
(0-1 \cdot 6)\end{array}$ & $\begin{array}{r}28.0 \\
\pm 11.2 \\
<0.005\end{array}$ & $\begin{array}{r}33 \cdot 8 \\
\pm 5 \cdot 4 \\
\text { NS }\end{array}$ & $\begin{array}{l}<1 \\
\text { Present in } 7 / 9 \\
\text { all }<1\end{array}$ & $\begin{array}{r}38 \cdot 1 \\
\pm 8 \cdot 2 \\
\text { NS }\end{array}$ & - & - \\
\hline
\end{tabular}

Table 2 Percent distribution of total bile acids in the proximal small intestine of azotaemic patients

Key as in Table 1. ND = not determined. 
cholic acid appeared to be lower in patients on chronic haemodialysis; the mean for the five nondialysed patients being $10.4 \%$ and the mean of patients on haemodialysis being $3.3 \%$. Ursodeoxycholic acid represented less than $1 \%$ of total bile acids in all normal subjects.

Keto bile acids, oxidized at the seven position, were identified in all of the azotaemic patients but were not noted in any of the normal subjects. 3,12dihydroxy-7-keto-cholanic acid was found in all the azotaemic patients with chromatograms suitable for analysis, while 3-hydroxy-7-keto-cholanic acid was found in all but one of these patients.

TOTAL BILE ACID CONCENTRATION

The mean total bile acid concentration in the proximal small intestine of normal subjects 30 minutes post-prandially was $3.3 \mu \mathrm{M} / \mathrm{ml}$ with a range of 0.4 to 10.2 . In the azotaemic population the mean bile acid concentration was $3.8 \mu \mathrm{M} / \mathrm{ml}$ with a range of 0.4 to 12.9 .

\section{CONJUGATED BILE ACID DISTRIBUTION}

The glycine/taurine conjugated bile acid ratio of proximal small intestinal contents of six azotaemic patients is reported in Fig. 1. Normal subjects had a mean glycine/taurine ratio of $3 \cdot 1$ with a range of 2.0 to $4 \cdot 3$, while azotaemic patients showed considerable scatter with a range of glycine/taurine ratios from 0.6 to 7.4 and a mean of 3.8 .

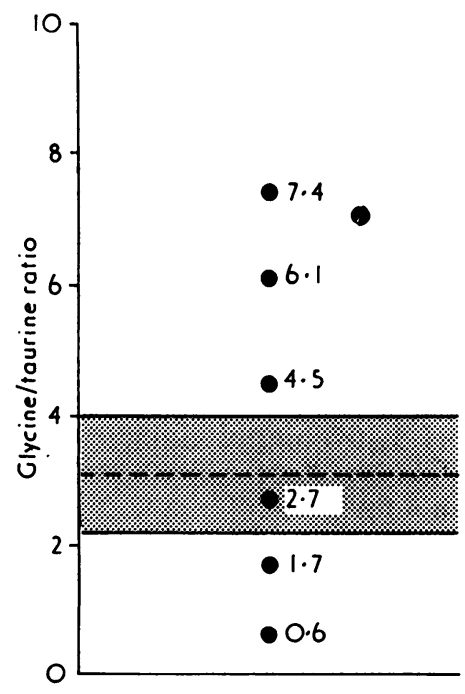

Fig. 1 Glycine/taurine conjugated bile acid ratio in the proximal small intestine in six azotaemic patients. The shaded area represents the range of nine normal subjects and the hatched line the normal mean.

\section{FAECAL BILE ACIDS}

The faecal total bile acid distribution in a normal subject is shown in Fig. 2a. There was a predominance of the secondary bile acids, lithocholic acid $(31 \%)$ and deoxycholic acid $(29 \%)$, and a bile acid metabolite, $3 \beta, 12 \alpha$-dihydroxy-cholanic acid $(12 \%)$. The primary bile acids, chenodeoxycholic acid $(4 \%)$ and cholic acid, were found in only small amounts. Ursodeoxycholic acid was also present $(3 \%)$. The remainder $(21 \%)$ of bile acid composition consisted of numerous bile acid metabolites with retention times different from the compounds studied. Un-
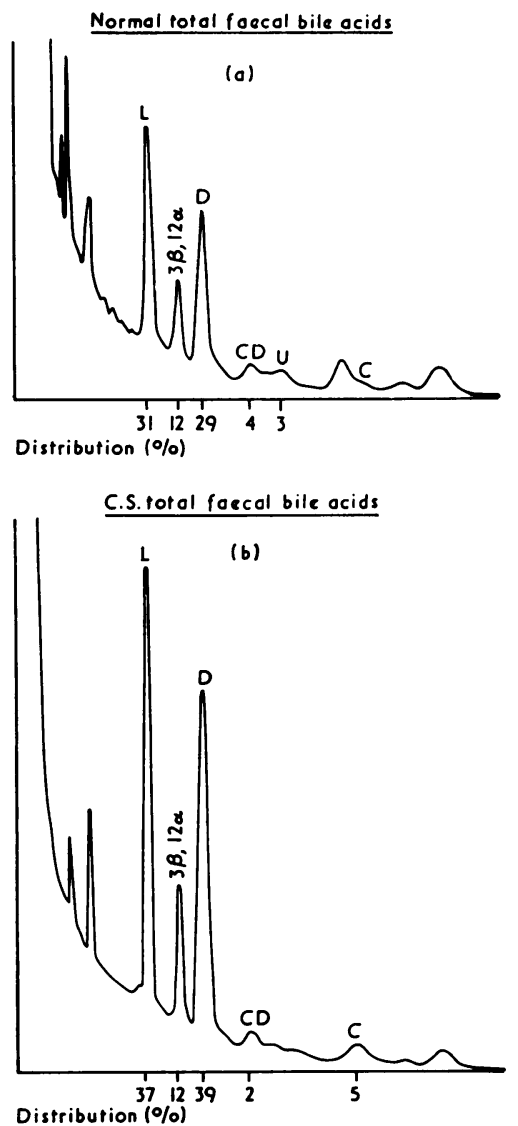

Fig. 2 (a) Gas liquid chromatogram of total faecal bile acids of a normal subject. The percent distribution of all identified bile acids is noted on the horizontal axis. $L=$ lithocholic acid, $3 \beta, 12 \alpha=3 \beta, 12 \alpha$-dihydroxy-cholanic acid, $D=$ deoxycholic acid, $C D=$ chenodeoxycholic acid, $\boldsymbol{U}=$ ursodeoxycholic acid, $\boldsymbol{C}=$ cholic acid.

(b) Gas liquid chromatogram of total faecal bile acids of an azotaemic patient (C.S.) with a normal percent deoxycholic acid in the proximal intestine. The percent distribution of all identified bile acids is noted on the horizontal axis. Abbreviations as noted above. 
conjugated bile acids represented greater than $95 \%$ of total faecal bile acids in this subject.

The total faecal bile acid pattern in an azotaemic patient (C.S.) with normal intestinal deoxycholic acid is shown in Fig. $2 b$. The chromatogram from this patient is similar to the normal faecal bile acid distribution, and, like the normal, unconjugated bile acids represented greater than $95 \%$ of the total faecal bile acids.

In contrast, the total faecal bile acid distribution
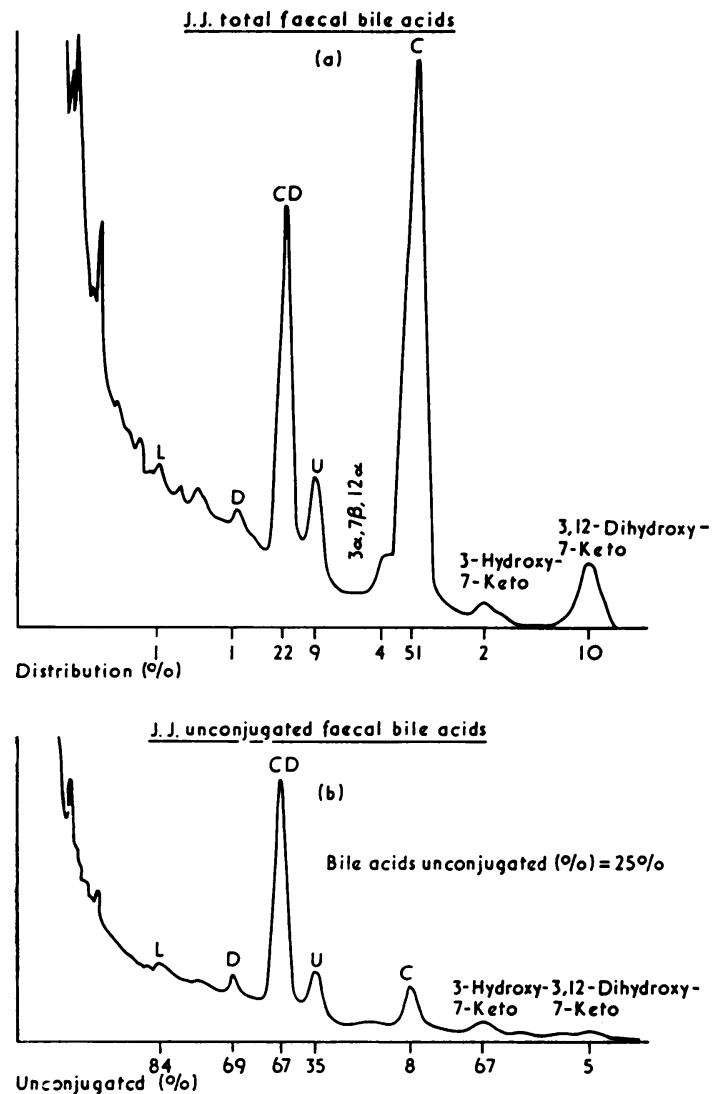

Fig. 3 (a) Gas liquid chromatogram of total faecal bile acids of an azotaemic patient (J.J.) with a low percent deoxycholic acid in the proximal intestine. The percent distribution of all identified bile acids is noted on the horizontal axis. $L=$ lithocholic acid, $D=$ deoxycholic acid, $C D=$ chenodeoxycholic acid, $U=$ ursodeoxycholic acid, $3 a, 7 \beta, 12 a=3 a, 7 \beta, 12 a$-trihydroxy-cholanic acid, $C=$ cholic acid, 3-hydroxy-7-keto $=3-$ hydroxy-7-keto-cholanic acid, 3,12-dihydroxy-7-keto $=3,12$-dihydroxy-7-ketocholanic acid. (b) Gas liquid chromatogram of unconjugated faecal bile acids from the same azotaemic patient (J.J.). This chromatogram represents an equivalent injection of the same faecal homogenate as shown in (a). The percentage of each bile acid present in the conjugated state is noted. Abbreviations as noted above. in one azotaemic patient with low intestinal deoxycholic acid (J.J. $-1.6 \%$ ) is shown in Fig. 3a. The bile acid distribution in this patient was entirely different from the normal. The secondary bile acids, lithocholic acid (1\%) and deoxycholic acid (1\%), were present in very low concentrations, while the primary bile acids, chenodeoxycholic acid (22\%) and cholic acid $(51 \%)$, were the predominant bile acids. In addition, ursodeoxycholic acid, $3 \alpha, 7 \beta, 12 \alpha$ trihydroxycholanic acid, 3-hydroxy-7-keto-cholanic acid, and 3,12-dihydroxy-7-keto-cholanic acid were present in measurable amounts.

Patient J.J., with predominantly primary faecal bile acids, demonstrated only $25 \%$ of faecal bile acids in unconjugated form. Chromatograms of the total faecal bile acids (a) and unconjugated faecal bile acids (b) in identical injections of the same sample of this patient are shown in Fig. 3. Lithocholic acid (84\%) and deoxycholic acid $(69 \%)$ were present predominantly in the unconjugated state. Significant amounts of chenodeoxycholic acid $(67 \%)$ and its oxidative metabolites, ursodeoxycholic acid $(35 \%)$ and 3-hydroxy-7-keto-cholanic acid (67\%) were found to be unconjugated. In contrast, cholic acid was only $8 \%$ unconjugated. Oxidative metabolites of cholic acid, $3 \alpha, 7 \beta, 12 \alpha$-trihydroxy-cholanic acid and 3,12-dihydroxy-7-keto-cholanic acid were essentially entirely in conjugated form.

The bile acid data at all levels of the gastrointestinal tract in patient J.J. are summarized in Table 3. Faecal secondary bile acids, lithocholic acid and deoxycholic acid, were very low, paralleling those in the intestinal lumen. Chenodeoxycholic acid showed a progressive decrease along the gastrointestinal tract, while cholic acid remained high, suggesting that more chenodeoxycholic acid than cholic acid was metabolized and/or absorbed.

$p H$

The $\mathrm{pH}$ of the small intestinal aspirates of normal subjects was: mean $6 \cdot 1$, range $2 \cdot 6-7 \cdot 6$, while, in azotaemic patients, the proximal intestinal $\mathrm{pH}$ was: mean $5 \cdot 7$, range $2 \cdot 5-7 \cdot 8$.

Faecal $\mathrm{pH}$ in five normal subjects ranged from 5.5 to 7 , while faecal $\mathrm{pH}$ in five azotaemic patients ranged from 6 to 8 .

\section{Discussion}

In this study, the most significant alteration in the intestinal bile acid pattern in azotaemic patients was a low deoxycholic acid. A number of possible mechanisms have been suggested to explain the finding of low deoxycholic acid in duodenal aspirates of patients suffering from a variety of diseases (Kern, 1973). In view of the diverse mechanisms 


\begin{tabular}{|c|c|c|c|}
\hline Bile acid (percent of total) & $\begin{array}{l}\text { Proximal } \\
\text { small intestine }\end{array}$ & Mid-ileum & Stool \\
\hline $\begin{array}{l}\text { Lithocholic acid } \\
\text { Deoxycholic acid } \\
\text { Chenodeoxycholic acid } \\
\text { Ursodeoxycholic acid } \\
3 a, 7 \beta, 12 a \text {-trihydroxy-cholanic acid } \\
\text { Cholic acid } \\
\text { 3-hydroxy-7-keto-cholanic acid } \\
\text { 3,12-dihydroxy-7-keto-cholanic acid } \\
\text { Percent free bile acids }\end{array}$ & $\begin{array}{c}3 \cdot 2 \\
1 \cdot 6 \\
42 \cdot 3 \\
3 \cdot 5 \\
0 \\
46 \cdot 7 \\
<1 \\
<1 \\
\text { ND }\end{array}$ & $\begin{array}{r}3 \cdot 9 \\
1 \cdot 3 \\
37 \cdot 1 \\
3 \cdot 2 \\
0 \\
51 \cdot 4 \\
<1 \\
<1 \\
1 \cdot 3\end{array}$ & $\begin{array}{r}0 \cdot 7 \\
1 \cdot 3 \\
22 \cdot 0 \\
8 \cdot 7 \\
4 \cdot 4 \\
51 \cdot 2 \\
1 \cdot 9 \\
9 \cdot 7 \\
25\end{array}$ \\
\hline
\end{tabular}

Table 3 Bile acid distribution at different levels of gastrointestinal tract in an azotaemic patient (J.J.)

proposed, it is appropriate to examine each of these theoretical possibilities to determine their applicability to the low deoxycholic acid noted in azotaemic patients.

Low deoxycholic acid has been described in patients with liver disease (Vlahcevic et al., 1971), but the routine liver function tests in all but two patients (L.M. and V.C., histological diagnosesTable 1) were normal at the time of testing. The deoxycholic acid level remains significantly low even with exclusion of these two patients from statistical analysis.

Resection of the terminal ileum has been shoun to be associated with low deoxycholic acid (McLeod and Wiggins, 1968; Mallory et al., 1973) but none of the patients studied had undergone bowel resection. The azotaemic patients studied did not show the high glycine/taurine ratios described in patients with terminal ileopathy or resection (McLeod and Wiggins, 1968; Bruusgaard and Thaysen, 1970; Mallory et al., 1973) and the glycine/taurine ratios in azotaemic patients did not correlate with the level of deoxycholic acid.

Since deoxycholic acid is a product of bacterial $7 \alpha$-dehydroxylation of cholic acid, appropriate microorganisms capable of performing this reaction must be present within the gastrointestinal tract. The azotaemic patients had an increased anaerobic population of the proximal small intestine (mean $8.6 \times 10^{6}$, range $10^{5}$ to $10^{7}$ ), and the predominant organisms were Bacteroides and Lactobacillus (Miller et al., 1974; Simenhoff, 1975), which are characteristically capable of enzymatic $7 \alpha$-dehydroxylation (Hill and Drasar, 1968; Midtvedt and Norman, 1968; Aries and Hill, 1970). Faecal anaerobes were also present in a range $10^{8}$ to $10^{10}$. For this reason, an insufficient bacterial population does not appear to be the cause of low deoxycholic acid.

Bacterial $7 \alpha$-dehydroxylation is $\mathrm{pH}$ dependent with a $\mathrm{pH}$ optimum for this reaction for different groups of microorganisms variously reported from 6-8 (Hill and Drasar, 1968; Aries and Hill, 1970).
Deoxycholic acid is predominantly formed in the colon and faecal $\mathrm{pH}$ in azotaemic patients was noted to be 6-8.

Anorexia or gallbladder dysfunction secondary to uraemic neuropathy could result in a decreased number of enterohepatic circulations yielding decreased production of deoxycholic acid. All azotaemic patients had a duodenal bile acid concentration within the normal range, 30 minutes post-prandially, suggesting adequate gallbladder emptying. Six patients had motor nerve conduction studies which were within normal limits (Table 1). Only two of the azotaemic patients had clinically significant anorexia.

Deoxycholic acid may be normally formed in the azotaemic colon but its absorption may be impaired. Defective absorption of bile acids in uraemia has not been excluded in this study and may be contributing to the low deoxycholic acid seen in this population. In patient, J.J., there was impaired synthesis of deoxycholic acid (Fig. 3), so that an absorptive defect cannot be universally responsible for the low deoxycholic acid seen in azotaemic patients.

Impaired synthesis of deoxycholic acid secondary to inhibition of $7 \alpha$-dehydroxylase has been demonstrated in vitro in the presence of excess substrate (cholic acid) concentration (Aries et al., 1969). The concentration of cholic acid in azotaemic patients was not measured at the level of the colon. However, in the proximal small intestine, abundant anaerobic microflora were found and the concentration of cholic acid at this level was below the inhibitory concentration described by Mitchell et al. (1974).

The azotaemic state itself may result in inhibition of bacterial enzymes including $7 \alpha$-dehydroxylase, secondary to retention of toxic materials in the gut lumen. Urea and guanidines have been demonstrated to act as competitive inhibitors of multiple enzyme systems, especially those which act on organic substrates (Rajagopalan et al., 1961) and luminal urea elevation in uraemic dogs has been noted to parallel that of the serum (Lee, 1971). Although luminal 
deoxycholic acid concentration is significantly lower in azotaemic patients than in normal subjects, luminal lithocholic acid, formed by $7 \alpha$-dehydroxylation of chenodeoxycholic acid, is present in all azotaemic patients. The stool of one azotaemic patient (J.J.), however, contained only very low concentrations of lithocholic acid. Low lithocholic acid in the stool of this patient in the presence of a significant amount of free chenodeoxycholic acid (Fig. 3b) suggests that there is some inhibition of bacterial $7 \alpha$-dehydroxylation.

Bacterial enzyme systems other than the $7 \alpha-$ dehydroxylases may also be inhibited in the presence of the azotaemic luminal milieu. Although Hepner and his colleagues (1972) have demonstrated that some dehydroxylation of conjugated bile acids may occur, the major substrate for dehydroxylation is unconjugated primary bile acids. If inhibition of bacterial hydrolases occurs in azotaemia, there will be insufficient substrate for dehydroxylation. Although the data available from this study are restricted to observations in one patient, there is some evidence that inhibition of bacterial bile acid hydrolases is occurring in this azotaemic patient with low deoxycholic acid. Normal faecal bile acid pattern (Fig. 2a) consists predominantly of free secondary bile acids, lithocholic acid and deoxycholic acid, and a bile acid metabolite, $3 \beta, 12 \alpha-$ dihydroxy-cholanic acid with little or no primary bile acids (Ali et al., 1966). Faecal bile acid analysis of J.J. (Fig. 3), reveals predominantly primary bile acids: $51 \%$ cholic acid, $22 \%$ chenodeoxycholic acid, with only $1 \%$ of each of lithocholic acid and deoxycholic acid. While normal subjects have all but a small amount of faecal bile acids in the unconjugated state (Norman, 1964), the faecal unconjugated bile acids in this patient constitute only $25 \%$ of the total bile acid composition. The small amount of lithocholic acid and deoxycholic acid present are predominantly in the unconjugated state. Chenodeoxycholic acid and its oxidative metabolites (ursodeoxycholic acid and 3-hydroxy7-keto-cholanic acid) are in significant degree unconjugated, while cholic acid and its oxidative metabolites $(3 \alpha, 7 \beta, 12 \alpha$-trihydroxy-cholanic acid and 3,12-dihydroxy-7-keto-cholanic acid) are essentially all in conjugated form. These data suggest that in this patient there is impairment of the conjugated cholic acid hydrolase reaction, with lesser impairment of the conjugated chenodeoxycholic acid hydrolase reaction and at least some impairment of the $7 \alpha-$ dehydroxylation of chenodeoxycholic acid. This phenomenon could account for the presence of very low deoxycholic acid in this patient. The proximal to distal bile acid pattern in this patient (Table 3) also confirms that there is more metabolism and/ or absorption of chenodeoxycholic acid than cholic acid.

If the mechanism postulated to account for the low deoxycholic acid in this patient be generally applicable to azotaemic patients, enzyme inhibition interfering with the production of free deoxycholic acid might be a contributing factor to the small intestinal overgrowth of bacteria observed in these patients. Floch et al. $(1971,1972)$ have demonstrated that free bile acids, especially free deoxycholic acid, inhibit bacterial growth in an in vitro system. Gorbach et al. (1967) have shown that the distal ileum is populated by bacterial flora from the colon, and Northfield and McColl (1973) have demonstrated a high concentration of free bile acids in the distal ileum. It seems likely that the presence of free bile acids at this level serves as a bacteriostatic mechanism to reduce the contamination of the small intestine by faecal flora. In azotaemics, therefore, the decrease in free bile acids, especially deoxycholic acid, might represent one factor allowing faecal bacterial contamination of the small intestine. In fact, the intestinal flora found in azotaemics is colonic in type (Miller et al., 1974).

Although the low deoxycholic acid described in azotaemic patients is a significant finding, the presence of low deoxycholic acid alone does not correlate with gastrointestinal symptoms in uraemic man. In addition to the low deoxycholic acid, there is a rather striking occurrence of unusual bile acids in intestinal aspirates of these patients. These bile acids represent the products of bacterial oxidation of the 7-hydroxyl of chenodeoxycholic acid and cholic acid to form keto bile acids (3-hydroxy-7keto-cholanic acid and 3,12-dihydroxy-7-ketocholanic acid). These keto bile acids may be reduced to compounds with the 7-hydroxyl group in the $\beta$ position (ursodeoxycholic acid and $3 \alpha, 7 \beta, 12 \alpha-$ trihydroxy-cholanic acid) as shown in Fig. 4. The two keto analogues were found in intestinal aspirates of all uraemic patients with chromatograms suitable for analysis (J.B. had only 3,12-dihydroxy-7-ketocholanic acid) and ursodeoxycholic acid was present in measurable concentration in all patients. $3 \alpha, 7 \beta, 12 \alpha$-trihydroxy-cholanic acid was tentatively identified in the stool of J.J. (Fig. 3).

In various bacterial species, in vitro studies of the bile acid 7-hydrogenase (oxidizing) enzyme system have shown several characteristics different from the dehydroxylating reaction. The enzymes are found in many aerobic organisms of the enteric type, the reaction can take place in cell-free systems, the $\mathrm{pH}$ optimum is higher $(8.8$ to $10 \cdot 2)$ and, although kinetics favour the deconjugated bile acid substrate, oxidation can occur using the conjugated bile acid as a substrate (Aries and Hill, 1970). These con- 


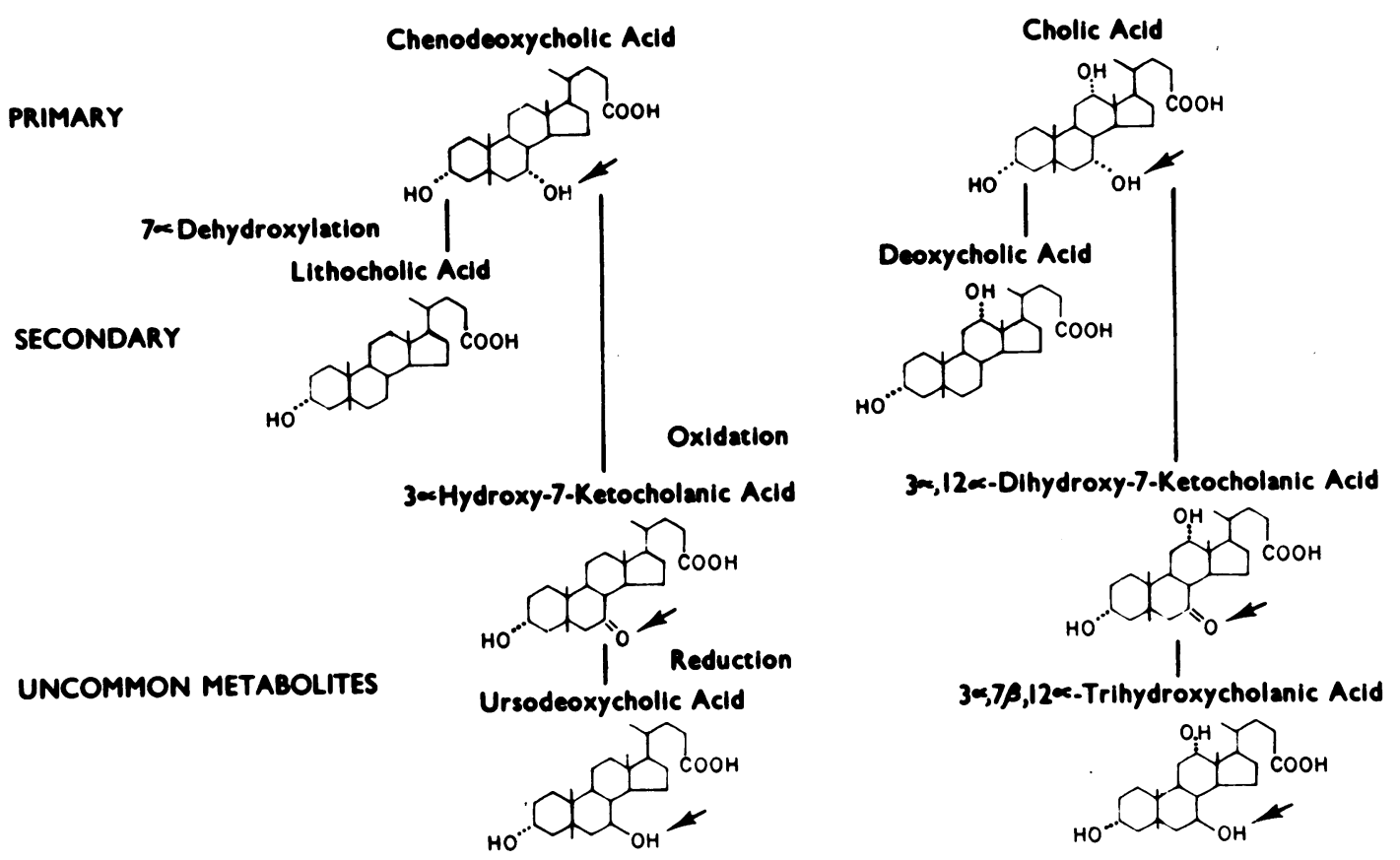

Fig. 4 Bacterial metabolism of the 7a-hydroxyl of bile acids (arrows) showing 7a-dehydroxylation and oxidation. Reduction of the 7-keto bile acid can yield the original bile acid with the 7-hydroxyl in the a position (dotted line) or a

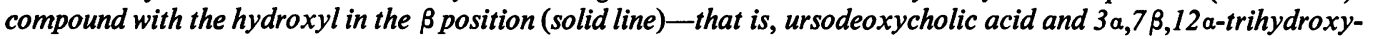
cholanic acid.

ditions favour the occurrence of this reaction in the azotaemic gut where colonic $\mathrm{pH}$ may be higher secondary to ammonia production from urea (Wrong, 1967), enteric organisms are plentiful, and conjugated bile acids may exist in the distal gastrointestinal tract.

The following sequence of events is postulated: the uraemic state impairs deconjugation and/or dehydroxylation of the primary bile acids, especially cholic acid. This process results in a decreased formation of the secondary bile acid, deoxycholic acid. The decrease in free bile acids may contribute to bacterial overgrowth of anaerobes and enteric organisms. These organisms are capable of oxidizing the 7-hydroxyl group of bile acids. With decreased dehydroxylation at the 7 position, an increased substrate is presented to the inducible dehydrogenating enzymes produced by these bacteria which can act on the conjugated bile acids. This results in the production of unusual bile acids-ursodeoxycholic acid, 3-hydroxy-7-keto-cholanic acid and 3,12dihydroxy-7-keto-cholanic acid.

When patients are grouped according to two factors-a normal or low level of deoxycholic acid and the level of ursodeoxycholic acid (Table 4)-a correlation with gastrointestinal symptoms becomes apparent. Patients with low deoxycholic acid and ursodeoxycholic acid greater than $3 \%$ of total bile acids have symptoms of watery diarrhoea. In this patient population, it appears that both of these bile acid abnormalities must be present for the symptom complex of diarrhoea to occur. Patients with normal deoxycholic acid do not have diarrhoea, even with ursodeoxycholic acid levels as high as $6 \%$, although other gastrointestinal symptoms such as nausea, vomiting, or constipation may be noted.

These symptoms parallel those in a patient with immunoglobulin deficiency syndrome described by Gleich and Hofmann (1971). This patient had diarrhoea with excess sodium and water in the stool associated with increased lithocholic acid and ursodeoxycholic acid associated with low deoxycholic acid $(7 \%)$. There was an apparent association of the abnormal bile acid pattern with diarrhoea since this patient responded to cholestyramine therapy. The similar bile acid pattern described in azotaemic patients with diarrhoea suggests that these bile acids may play a role in the bowel dysfunction described in uraemic man. The exact nature of this role is uncertain; however, keto bile acids have been shown to affect membrane ATPases in rat intestinal mucosa (Hepner and Hofmann, 1973) and also in 


\begin{tabular}{|c|c|c|c|c|}
\hline$P t$ & $\% D^{*}$ & $\% U_{\dagger}$ & Clinical symptoms & $\begin{array}{l}\text { Stools per } \\
\text { day (no.) }\end{array}$ \\
\hline \multicolumn{5}{|c|}{ Patients with low percent deoxycholic acid in proximal small intestine } \\
\hline E.C. & 4.9 & $15 \cdot 6$ & Severe watery diarrhoea, weight loss & $10-15$ \\
\hline W.P. & $10 \cdot 2$ & $10 \cdot 3$ & Severe watery diarrhoea, weight loss, nausea and vomiting & $10-15$ \\
\hline A.H. & $1 \cdot 0$ & $7 \cdot 9$ & Severe watery diarrhoea & 10 \\
\hline L.M. & $12 \cdot 2$ & $6 \cdot 0$ & Mild diarrhoea, nausea and vomiting & 3 \\
\hline V.C. & $1 \cdot 6$ & $2 \cdot 5$ & Anorexia, nausea with onset of jaundice & 1 \\
\hline S.G. & $13 \cdot 7$ & $1 \cdot 5$ & $\begin{array}{l}\text { Severe watery diarrhoea post-vagotomy and pyloroplasty ; } \ddagger \text { formerly asymptomatic on } \\
\text { haemodialysis }\end{array}$ & $8-10$ \\
\hline L.A. & 3.8 & 1.5 & Asymptomatic on chronic haemodialysis (predialysis diarrhoea) & 2 \\
\hline \multicolumn{5}{|c|}{ Patients with normal percent deoxycholic acid in proximal small intestine } \\
\hline J.B. & $28 \cdot 4$ & $6 \cdot 2$ & Severe nausea and vomiting & 1 \\
\hline M.E. & $24 \cdot 9$ & $4 \cdot 7$ & Constipation & $0-1$ \\
\hline H.D. & $23 \cdot 7$ & $2 \cdot 4$ & Asymptomatic without haemodialysis & 1 \\
\hline C.F. & $16 \cdot 8$ & 1.4 & Asymptomatic on chronic haemodialysis (predialysis diarrhoea) & 2 \\
\hline
\end{tabular}

Table 4 Ursodeoxycholic acid correlated with clinical status

*Deoxycholic acid.

+Ursodeoxycholic acid.

$\ddagger$ Diarrhoea presumed secondary to increased faecal dihydroxy bile acid loss occurring post-vagotomv.

liver canalicular plasma membranes (Nemchausky et al., 1975) and to interact with bile acids at the membrane level, which may result in an altered intestinal secretory pattern. Cholestyramine was not given to any uraemic patient in this series. The role of bacterial overgrowth was not assessed in the patient described by Gleich and Hofmann (1971). The interrelationship between bacterial overgrowth and this abnormal bile acid pattern remains to be elucidated.

Ursodeoxycholic acid is lower in those patients on chronic dialysis than in those patients who have never undergone haemodialysis. While no patient was studied before and after haemodialysis for the level of ursodeoxycholic acid, several patients noted improvement in diarrhoeal symptoms associated with chronic haemodialysis.

In summary, it appears from this series of patients that an abnormal bile acid pattern characterized by low deoxycholic acid and increased ursodeoxycholic acid and keto bile acids is characteristic of azotaemic patients with diarrhoea, and may contribute to the pathogenesis of this diarrhoea.

This work was supported in part by NIH-NIAMD contract 72-2209. Project Themis Contract N0001468-A-0516, Office of Naval Research, provided the gas liquid chromatography equipment. Dr Kinsey was supported by NIH-NIAMD training grant 2T01-AM5572. The authors wish to acknowledge the valuable contributions of $\mathrm{Dr}$ James Burke, Joanne Magen, Dr Jussi Saukkonen, Dr Michael Simenhoff, and Joyce Spainhour, to this study. We gratefully acknowledge the skilled secretarial assistance of Ms Sue Direnzo.

\section{References}

Ali, S. S., Kuksis, A., and Beveridge, J. M. R. (1966). Excretion of bile acids by three men on a fat-free diet. Canadian Journal of Biochemistry, 44, 957-969.

Aries, V., Crowther, J. S., Drasar, B. S., and Hill, M. J. (1969). Degradation of bile salts by human intestinal bacteria. Gut, 10, 575-576.

Aries, V., and Hill, M. J. (1970). Degradation of steroids by intestinal bacteria: 2. Enzymes catalysing the oxidoreduction of the 3a-, 7a-, and 12a-hydroxyl groups in cholic acid, and the dehydroxylation of the 7-hydroxyl group. Biochimica et Biophysica Acta, 202, 535-543.

Bruusgaard, A. (1970). Quantitative determination of the major 3-hydroxy bile acids in biological material after thin-layer chromatographic separation. Clinica Chimica Acta, 28, 495-504.

Bruusgaard, A., and Thaysen, E. H. (1970). Increased ratio of glycine/taurine conjugated bile acids in the early diagnosis of terminal ileopathy: Preliminary report. Acta Medica Scandinavica, 188, 547-548.

Drüeke, T., Ganeval, D., and Marche, C. (1972). Effect of sodium deoxycholate on net transintestinal movement in the uraemic rat: acute experiments. Experientia, 28, 1334-1335.

Einheber, A., and Carter, D. (1966). The role of the microbial flora in uremia: 1. Survival times of germfree, limitedflora, and conventionalized rats after bilateral nephrectomy and fasting. Journal of Experimental Medicine, 123, 239-250.

Floch, M. H., Binder, H. J., Filburn, B., and Gershengoren, W. (1972). The effect of bile acids on intestinal microflora. American Journal of Clinical Nutrition, 25, 1418-1426.

Floch, M. H., Gershengoren, W., Elliott, S., and Spiro, H. M. (1971). Bile acid inhibition of the intestinal microflora- a function for simple bile acids? Gastroenterology, 61, 228-233.

Giovannetti, S., and Maggiore, Q. (1964). A low-nitrogen diet with proteins of high biological value for severe chronic uraemia. Lancet, 1, 1000-1003.

Gleich, G. J., and Hofmann, A. F. (1971). Use of cholestyramine to control diarrhea associated with acquired hypogammaglobulinemia. American Journal of Medicine, 51, 281-286. 
Gorbach, S. L., Plaut, A. G., Nahas, L., and Weinstein, L. (1967). Studies of intestinal microflora: 2.|Microorganisms of the small intestine and their relations to oral and fecal flora. Gastroenterology, 53, 856-867.

Grundy, S. M., Ahrens, E. H., Jr, and Miettinen, T. A. (1965). Quantitative isolation and gas-liquid chromatographic analysis of total fecal bile acids. Journal of Lipid Research, 6, 397-410.

Haeffner, L. J., Gordon, S. J., Strum, S., Elliot, M., and Kowlessar, O. D. (1976a). Analysis of the total bile acid distribution in human intestinal aspirates by gas liquid chromatography. Annals of Clinical and Laboratory Science. (In press.)

Haeffner, L. J., Gordon, S. J., Strum, S., Elliot, M., and Kowlessar, O. D. (1976b). Analysis of the conjugated bile acid distribution in human intestinal aspirates using gas liquid chromatography. Annals of Clinical and Laboratory Science. (In press.)

Hepner, G. W., and Hofmann, A. F. (1973). Different effects of free and conjugated bile acids and their keto derivatives on $\left(\mathrm{Na}^{+}, \mathrm{K}^{+}\right)$-stimulated and $\mathbf{M g}^{2}$ ATPase of rat intestinal mucosa. Biochimica et Biophysica Acta, 291, 237-245.

Hepner, G. W., Hofmann, A. F., and Thomas, P. J. (1972). Metabolism of steroid and amino acid moieties of conjugated bile acids in man. 1. Cholylglycine. Journal of Clinical Investigation, 51, 1889-1897.

Hill, M. J., and Drasar, B. S. (1968). Degradation of bile salts by human intestinal bacteria. Gut, 9, 22-27.

Hofmann, A. F. (1962). Thin-layer adsorption chromatography of free and conjugated bile acids on silicic acid. Journal of Lipid Research, 3, 127-129.

Iwata, T., and Yamasaki, K. (1964). Enzymatic determination and thin-layer chromatography of bile acids in blood. Journal of Biochemistry (Tokyo), 56, 424-431.

Jaffe, R. H., and Laing, D. R. (1934). Changes of the digestive tract in uremia: a pathologic anatomic study. Archives of Internal Medicine, 53, 851-864.

Kern, F., Jr (1973). Disappearance of deoxycholic acid after ileal resection. Gastroenterology, 64, 123-127.

Lee, Y. N. (1971). Urea concentration in intestinal fluids in normal and uremic dogs. Journal of Surgical Oncology, $3,163-168$.
McLeod, G. M., and Wiggins, H. S. (1968). Bile-salts in small intestinal contents after ileal resection and in other malabsorption syndromes. Lancet, 1, 873-876.

Mallory, A., Kern, F., Jr, Smith, J., and Savage, D. (1973). Patterns of bile acids and microflora in the human small intestine. 1. Bile acids. Gastroenterology, 64, 26-33.

Midtvedt, T., and Norman, A. (1968). Parameters in $7 a$-dehydroxylation of bile acids by anaerobic lactobacilli. Acta Pathologica et Microbiologica Scandinavica 72, 313-329.

Miller, L. J., Gordon, S. J., Haeffner, J. J., Saukkonen, J. J., Kinsey, M. D., and Kowlessar, O. D. (1974). Bile acid abnormalities in uremic man. (Abstr.) Gastroenterology, 66, 746.

Mitchell, W. D., Findlay, J. M., Macrae, R., Eastwood, M. A., and Anderson, R. (1974). Factors affecting bile acid metabolism in cholerrheic enteropathy. Digestion, 11, 135-146.

Nemchausky, B., Reno, D., and Boyer, J. L. (1975). Synthetic and naturally occurring bile salts-modifiers of ATPase activity in canalicular enriched liver plasma membranes. (Abstr.) Clinical Research, 23, 254A.

Norman, A. (1964). Faecal excretion products of cholic acid in man. British Journal of Nutrition, 18, 173-186.

Northfield, T. C., and McColl, I. (1973). Postprandial concentrations of free and conjugated bile acids down the length of the normal human small intestine. Gut, 14, 513-518.

Rajagopalan, K. V., Fridovich, I., and Handler, P. (1961). Competitive inhibition of enzyme activity by urea. Journal of Biological Chemistry, 236, 1059-1065.

Simenhoff, M. L. (1975). Metabolism and toxicity of aliphatic amines. Kidney International, 7, S. 314-317.

Sjövall, J. (1962). Qualitative analysis of bile acids by gas chromatography: bile acids and steroids 124. Acta Chemica Scandinavica, 16, 1761-1764.

Vlahcevic, Z. R., Buhac, I., Farrar, J. T., Bell, C. C., and Swell, L. (1971). Bile acid metabolism in patients with cirrhosis: 1. Kinetic aspects of cholic acid metabolism. Gastroenterology, 60, 491-498.

Wrong, O. (1967). The metabolism of urea and ammonia in the healthy and uraemic colon. MedicalJournal of Australia, 2, 281-283. 